\title{
Colon Cancer-associated Fibroblast Establishment and Culture Growth
}

Mercedes Herrera ${ }^{1}$, Alberto Herrera ${ }^{1}$, María Jesús Larriba² ${ }^{2}$, Gemma Ferrer-Mayorga ${ }^{2}$, Antonio García de Herreros ${ }^{3}$, Félix Bonilla ${ }^{4}$, Josep Baulida ${ }^{3^{*}}$ and Cristina Peña ${ }^{{ }^{*}}$

${ }^{1}$ Grupo de investigación en "Señalización celular en cáncer", Hospital Universitario Puerta de Hierro de Majadahonda, Majadahonda, Madrid, Spain; ${ }^{2}$ Instituto de Investigaciones Biomédicas "Alberto Sols", Consejo Superio de Investigaciones Científicas, Universidad Autónoma de Madrid, IdiPAZ, Madrid, Spain; ${ }^{3}$ Programa de Recerca en Cáncer, Institut Hospital del mar d'Investigacions Mèdiques, Barcelona, Spain; ${ }^{4}$ Centro de Estudios Biosanitarios, Madrid, Spain

*For correspondence: cpena@idiphim.org and jbaulida@imim.es

[Abstract] Cancer-associated fibroblasts (CAFs) are one of the major players in tumor-stroma crosstalk. Findings in experimental studies suggest important roles for CAFs in regulation of tumor growth, metastasis and drug response (Hanahan and Coussens, 2012). Furthermore, their clinical relevance is supported by new findings from tumor analyses, demonstrating the prognostic and response-predictive significance of CAF-derived markers or gene signatures (Berdiel-hacer et al., 2014; Finak et al., 2008; Navab et al., 2011; Paulsson and Micke, 2014). CAFs are a heterogeneous pool of cell subsets with distinct functions which needs to be better defined by their marker expressions. The development of a methodology for the establishment of fibroblast primary cultures derived from human colon tumors allowed us to characterize their functional and molecular properties (Herrera et al., 2013). In addition, the different molecular mechanisms through which CAFs affect tumor growth and metastasis are still to be clarified. Therefore, functional and molecular characterization of the cancer-associated fibroblasts is essential to fully understand their role in tumor progression.

\section{Materials and Reagents}

1. $50 \mathrm{ml}$ Falcon tubes

2. Sterile disposable plastic Pasteur pipettes or sterile forceps

3. $10 \mathrm{~cm}$ tissue culture dishes

4. T-25 tissue culture flasks

5. MW6 tissue culture plates (Jet Biofil, catalog number: TCP-011-006)

6. Human tissue samples (colon normal and tumor tissue)

7. Dulbecco's Modified Eagle Medium (DMEM) high glucose without L-glutamine (Lonza, catalog number: BE12-614F)

8. L-glutamine (Lonza, catalog number: BE17-605E)

9. Normocin ${ }^{\mathrm{TM}}$ (InvivoGen, catalog number: ANT-NR-2)

10. Penicillin/Streptomycin (Lonza, catalog number: BE17-602E) 


\section{biö-protocol}

11. Amphotericin B (Carl Roth $\mathrm{GmbH}+$ Co., catalog number: 0246.1)

12. Gentamicin (Carl Roth $\mathrm{GmbH}+$ Co., catalog number: 0233.2)

13. Phosphate-buffered saline (PBS) (Lonza, catalog number: BE17-516F)

14. Fetal Bovine Serum medium (FBS) (Biowest, catalog number: S181B-500)

15. Trypsin/EDTA (Thermo Fisher Scientific, Gibco ${ }^{T M}$, catalog number: 25200-056)

16. FBM \& FGM-2 Bullet kit [Lonza, catalog number:(CC-3131) and (CC-4126)] Note: FBM \& FGM-2 Bullet kit is on the list of Fibroblast Growth Media (FGM) Kits] (Lonza, catalog number: CC-3132).

17. DMEM (see Recipes)

18. FBS with high concentration of antibiotics (see Recipes)

19. FBS with normal concentration of antibiotics (see Recipes)

\section{Equipment}

1. Laminar flow tissue culture hood

2. Scalpels

3. $37^{\circ} \mathrm{C}$ shaker

4. $37^{\circ} \mathrm{C}$ and $5 \% \mathrm{CO}_{2}$ cell culture incubator

5. Centrifuge

\section{Procedure}

A. Before starting

1. Immediately after surgery, colon normal and tumor tissues are preserved in Falcon tubes with $10 \mathrm{ml}$ of DMEM with a high concentration of antibiotics to avoid bacterial or fungal contamination. To this end, DMEM is supplemented with $5 \%$ FBS, L-glutamine (1\%), $300 \mathrm{U} / \mathrm{ml}$ Penicillin, $300 \mu \mathrm{g} / \mathrm{ml}$ Streptomycin and $5 \mu \mathrm{g} / \mathrm{ml}$ Amphotericin B.

2. Tissue samples are kept at $4{ }^{\circ} \mathrm{C}$ until use. It is recommended to minimize the time between the colon surgery and the processing of the sample.

3. Make sure that you have all the necessary materials, reagents and equipment.

B. Washing samples: Normal mucosa and tumor material

1. Falcon tubes with human tissue samples from colon tumor or normal mucosa are placed into a laminar flow tissue culture hood under sterile conditions. The average size of tissues required is $1 \mathrm{~cm}^{2}$. 


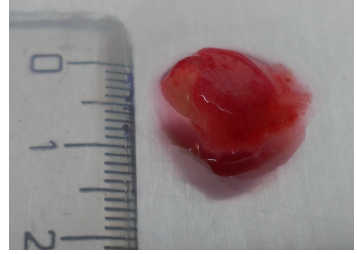

Figure 1. Surgical colon human samples. Representative images of tumor tissue sample to show the used average size.

2. Perform two quick washes of the tissue samples with $10 \mathrm{ml}$ PBS each time using Falcon tubes and Pasteur pipettes to handle the samples.

3. Then, incubate the samples for $30 \mathrm{~min}$ in $10 \mathrm{ml}$ of PBS with $0.5 \mathrm{mg} / \mathrm{ml} \mathrm{Normocin,} 0.5$ $\mu \mathrm{g} / \mathrm{ml}$ Amphotericin B and $0.1 \mathrm{mg} / \mathrm{ml}$ Gentamicin in the Falcon tubes. Shake gently in a $37^{\circ} \mathrm{C}$ shaker.

C. Dissecting and seeding samples: Normal mucosa and tumor material

1. Tissue samples are transferred to a $10 \mathrm{~cm}$ tissue culture dish. Do not let the samples dry out at this point.

2. The samples are carefully analyzed: normal tissue is fatty and soft, while tumor tissue is stiff, multimodular to variable degrees, and sometimes displays more irrigated areas.

3. Cut the tissue samples into pieces of approximately $2-3 \mathrm{~mm}^{3}$ by scalpels.

4. Use Pasteur pipettes or sterile forceps to seed tissue pieces in T-25 tissue culture flasks with $2 \mathrm{ml}$ of FBS supplemented with $0.2 \mathrm{mg} / \mathrm{ml}$ Normocin, $200 \mathrm{U} / \mathrm{ml}$ Penicillin, $200 \mu \mathrm{g} / \mathrm{ml}$ Streptomycin and $0.1 \mathrm{mg} / \mathrm{ml}$ Gentamicin (Hanahan and Coussens, 2012). We call this medium "FBS with high concentration of antibiotics". Incubate the $\mathrm{T}-25$ flasks at $37^{\circ} \mathrm{C}$ in a humid atmosphere containing $5 \% \mathrm{CO}_{2}$.

5. After $24 \mathrm{~h}$, it is quite useful to remove culture medium from the T-25 flasks, wash twice with PBS, and add fresh "FBS with high concentration of antibiotics" medium. When changing the medium, be careful and try to keep the pieces stuck on the plate. If after two days bacterial or fungal contamination does not appear, it is optional to change the medium to "FBS with normal concentration of antibiotics" (Berdiel-hacer et al., 2014): FBS with $0.1 \mathrm{mg} / \mathrm{ml}$ Normocin, $100 \mathrm{U} / \mathrm{ml}$ Penicillin and $100 \mu \mathrm{g} / \mathrm{ml}$ Streptomycin. However, if contamination persists, continue using "FBS with high concentration of antibiotics". If after five days contamination has not disappeared, discard the samples.

6. Normally, outgrowths of fibroblasts appear after 10 days and the culture medium is replaced by FBM supplemented with FGM-2 Bulletkit to facilitate fibroblast growth (Finak et al., 2008). The fibroblastic cells are routinely maintained in FBM medium at $37{ }^{\circ} \mathrm{C}$ in a humid atmosphere containing $5 \% \mathrm{CO}_{2}$. Change the medium every two days. 


\section{biö-protocol}

D. Expansion of fibroblast primary cell cultures

1. After 30-40 days, when the cell culture is usually quite large (see Figure 1), the remnants of the tissue are removed giving a light tap to the flask.

2. Fibroblasts are washed twice with PBS and trypsinized by Trypsin/EDTA for $5 \mathrm{~min}$ at $37^{\circ} \mathrm{C}$. Use serum medium (FBS) to block the trypsin activity and centrifuge at 1,200 rpm during 5 min. After that, seed the fibroblasts cells in MW6 tissue plates using FBM medium.

3. Then, fibroblast primary cultures are subcultured at a 1 to 2 ratio (Navab et al., 2011) in FBM medium and maintained at $37{ }^{\circ} \mathrm{C}$ in a humid atmosphere containing $5 \% \mathrm{CO}_{2}$. Change the medium every two days. Primary CAFs initially show bi- and/or multi-polar morphology and then acquired a uniform spindle-shaped morphotype and formed parallel arrays and whorls at confluence. Expression of $\alpha$-sma and Vimentin and the absence of Pan Cytokeratin (PanCK) could be analyzed by immunofluorescence to verify the CAF enrichment in the cell culture as was done in Herrera et al. (2013).

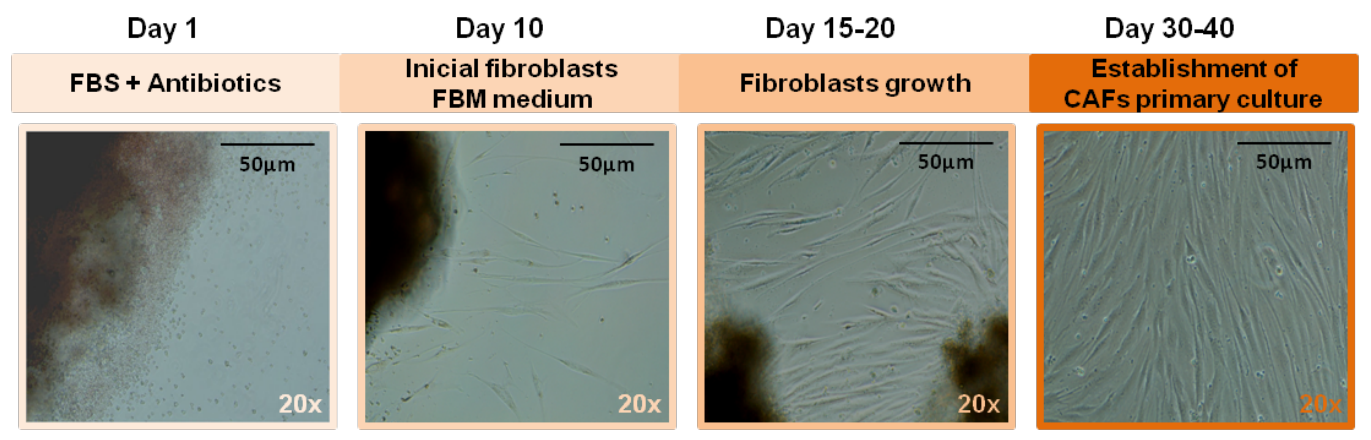

Figure 2. Establishment and characterization of primary CAFs from colon cancer patients. Representative images of CAF cultures along the establishment time. Scale bar $=50 \mu \mathrm{m}$

\section{Recipes}

1. DMEM

$5 \%$ FBS

L-glutamine (1\%)

$300 \mathrm{U} / \mathrm{ml}$ Penicillin

$300 \mu \mathrm{g} / \mathrm{ml}$ Streptomycin

2. $5 \mu \mathrm{g} / \mathrm{ml}$ Amphotericin BFBS with high concentration of antibiotics

FBS supplemented with $0.2 \mathrm{mg} / \mathrm{ml}$ Normocin, $200 \mathrm{U} / \mathrm{ml}$ Penicillin, $200 \mu \mathrm{g} / \mathrm{ml}$ Streptomycin and $0.1 \mathrm{mg} / \mathrm{ml}$ Gentamicin (Hanahan and Coussens, 2012)

3. FBS with normal concentration of antibiotics

FBS with $0.1 \mathrm{mg} / \mathrm{ml}$ Normocin, $100 \mathrm{U} / \mathrm{ml}$ Penicillin and $100 \mu \mathrm{g} / \mathrm{ml}$ Streptomycin 


\section{$\underline{\text { Notes }}$}

1. We recommend not putting more than 5-6 pieces in each T25 flask, which helps control contamination. Use several flasks per sample if you need to do so.

2. We prefer to use the medium "FBS with high concentration of antibiotics" for 7-10 days (replace with fresh medium every two days).

3. We recommend changing the medium to FBM after 12-14 days even if fibroblasts are not seen.

4. Cell numbers can be expanded minimally, though bear in mind that primary cells enter senescence after prolonged in vitro culture. Immortalization can be performed using adequate procedures (Navab et al., 2011).

\section{Acknowledgments}

This protocol is an extended version of the one described in Herrera et al. (2013) and Stanisavljevic et al. (2015).

M. Eaude helped with the English text. This research is supported by PI12/02037, RD12/0036/0041 and RD12/0036/0021 from the Instituto de Salud Carlos III-FEDER; by the Fundación Científica AECC; by SAF2010-20750 from the Ministerio de Economía y Competitividad of Spain-FEDER; by S2010/BMD-2344 from the Comunidad de Madrid; and by the Fundación Banco Santander. Antonio García de Herreros' laboratory is supported by RD12/0036/0005 (from the Instituto de Salud Carlos III-FEDER) and SAF2013-48849-C2-1-R (from the Ministerio de Economía y Competitividad of Spain-FEDER). Cristina Peña is a recipient of a Miguel Servet Contract from the Instituto de Salud Carlos III. All authors state no conflicts of interest. We thank lab members for help and advice throughout this research.

\section{References}

1. Berdiel-Acer, M., Berenguer, A., Sanz-Pamplona, R., Cuadras, D., Sanjuan, X., Paules, M. J., Santos, C., Salazar, R., Moreno, V., Capella, G., Villanueva, A. and Mollevi, D. G. (2014). A 5-gene classifier from the carcinoma-associated fibroblast transcriptomic profile and clinical outcome in colorectal cancer. Oncotarget 5(15): 6437-6452.

2. Finak, G., Bertos, N., Pepin, F., Sadekova, S., Souleimanova, M., Zhao, H., Chen, H., Omeroglu, G., Meterissian, S., Omeroglu, A., Hallett, M. and Park, M. (2008). Stromal gene expression predicts clinical outcome in breast cancer. Nat Med 14(5): 518-527.

3. Hanahan, D. and Coussens, L. M. (2012). Accessories to the crime: functions of cells recruited to the tumor microenvironment. Cancer Cell 21(3): 309-322. 


\section{biö-protocol}

4. Herrera, M., Islam, A. B., Herrera, A., Martin, P., Garcia, V., Silva, J., Garcia, J. M., Salas, C., Casal, I., de Herreros, A. G., Bonilla, F. and Pena, C. (2013). Functional heterogeneity of cancer-associated fibroblasts from human colon tumors shows specific prognostic gene expression signature. Clin Cancer Res 19(21): 5914-5926.

5. Navab, R., Strumpf, D., Bandarchi, B., Zhu, C. Q., Pintilie, M., Ramnarine, V. R., Ibrahimov, E., Radulovich, N., Leung, L., Barczyk, M., Panchal, D., To, C., Yun, J. J., Der, S., Shepherd, F. A., Jurisica, I. and Tsao, M. S. (2011). Prognostic gene-expression signature of carcinoma-associated fibroblasts in non-small cell lung cancer. Proc Natl Acad Sci U S A 108(17): 7160-7165.

6. Paulsson, J. and Micke, P. (2014). Prognostic relevance of cancer-associated fibroblasts in human cancer. Semin Cancer Biol 25: 61-68. 